

\section{MICROSOFT EXCEL-BASED TOOL KIT FOR PLANNING HYBRID ENERGY SYSTEMS}

A User Guide 
(C) 2017 Asian Development Bank

6 ADB Avenue, Mandaluyong City, 1550 Metro Manila, Philippines

Tel +632632 4444; Fax +6326362444

www.adb.org

Some rights reserved. Published in 2017.

ISBN 978-92-9257-975-3 (print), 978-92-9257-976-0 (electronic)

Publication Stock No. TIM179087-2

DOI: http://dx.doi.org/10.22617/TIM179087-2

The views expressed in this publication are those of the authors and do not necessarily reflect the views and policies of the Asian Development Bank (ADB) or its Board of Governors or the governments they represent.

ADB does not guarantee the accuracy of the data included in this publication and accepts no responsibility for any consequence of their use. The mention of specific companies or products of manufacturers does not imply that they are endorsed or recommended by ADB in preference to others of a similar nature that are not mentioned.

By making any designation of or reference to a particular territory or geographic area, or by using the term "country" in this document, ADB does not intend to make any judgments as to the legal or other status of any territory or area.

This work is available under the Creative Commons Attribution 3.0 IGO license (CC BY 3.0 IGO)

https://creativecommons.org/licenses/by/3.0/igo/. By using the content of this publication, you agree to be bound by the terms of this license. For attribution, translations, adaptations, and permissions, please read the provisions and terms of use at https://www.adb.org/terms-use\#openaccess

This CC license does not apply to non-ADB copyright materials in this publication. If the material is attributed to another source, please contact the copyright owner or publisher of that source for permission to reproduce it. $A D B$ cannot be held liable for any claims that arise as a result of your use of the material.

Please contact pubsmarketing@adb.org if you have questions or comments with respect to content, or if you wish to obtain copyright permission for your intended use that does not fall within these terms, or for permission to use the ADB logo.

Notes:

In this publication, “\$” refers to US dollars.

Corrigenda to ADB publications may be found at http://www.adb.org/publications/corrigenda 


\section{CONTENTS}

Acknowledgments $\quad v$

Abbreviations

1. Introduction 1

$\begin{array}{lll}1.1 & \text { Background and Context } & 1\end{array}$

1.2 About this Microsoft Excel-Based Workbook 1

2. Input Data for the Workbook 3

2.1 Project Data 3

2.2 Load Demand 5

2.3 Diesel Generators 6

2.4 Wind Resource 9

2.5 Wind Turbines 12

2.6 Solar Resource 14

$\begin{array}{ll}2.7 \text { Photovoltaic Arrays } & 16\end{array}$

$\begin{array}{ll}2.8 \text { Electric Battery Storage System } & 18\end{array}$

3. Workbook Results 25

3.1 Operation 25

3.2 Running the Macro 25

4. Annex: Detailed Calculations 27

$\begin{array}{ll}4.1 \text { Wind Speed Values } & 27\end{array}$

$\begin{array}{ll}\text { 4.2 Solar Radiation Values } & 28\end{array}$

$\begin{array}{ll}4.3 \text { Simulation of the Operation } & 31\end{array}$

$\begin{array}{ll}\text { References } & 35\end{array}$ 


\section{FIGURES AND TABLES}

\section{Figures}

1 Project Data 5

2 Load Input Sheet 6

3 Fuel Consumption and its Corresponding Efficiency

Curve of a Diesel Generator $\quad 7$

4 Diesel Generators Input Data 8

$5 \quad$ Weibull Probability Distribution for Different Values of $k$ (left) and A (right)

6 Wind Resource Input Data 11

7 Wind Turbine Power Curve 12

$8 \quad$ Wind Turbines Input Data 13

9 Solar Resource Input Data $\quad 15$

10 Average Solar Radiation and Clearness Index $\quad 15$

11 Photovoltaic Panels Angles 17

\section{Tables}

1 Project Data 3

2 Diesel Generators Input Data 6

3 Wind Resource Input Data 9

$4 \quad$ Wind Turbines Data 12

5 Solar Resource Input Data $\quad 14$

6 Photovoltaic Installations Input Data 16 


\section{ACKNOWLEDGMENTS}

his technical report was prepared under a regional technical assistance (TA) financed
by the Asian Development Bank (ADB) (ADB. 2009. Effective Deployment of
Distributed Small Wind Power Systems in Asian Rural Areas. Manila). The TA aimed to
help its developing member countries to provide reliable, adequate, and affordable energy
for inclusive growth. Originally focused at deploying small wind power systems, the TA
has subsequently evolved to cover hybrid renewable energy systems including wind, solar,
battery storage, and efficient diesel generation systems.

The report draws on activities related to the deployment and implementation of four pilot hybrid renewable systems in minigrids that were installed and commissioned in Maldives (two systems), Sri Lanka, and Bangladesh. The work on this report began in early 2015 and was completed in May 2017, building on findings from the real case studies in these countries. The ultimate goal of the report is to provide relevant technical guidance and recommendations for effective deployment of hybrid renewable energy systems in minigrids to achieve universal electricity access and energy efficiency in remote rural locations and small isolated islands.

The technical report was prepared by José A. Aguado (jaguado@uma.es) of the University of Malaga (and of consulting firm Effergy Energia in Spain), who was engaged as an ADB consultant for the tasks related to implementing the hybrid renewable energy systems under the TA, and Mukhtor Khamudkhanov, principal energy specialist, Energy Division, South Asia Department, $A D B$, who supervised the work on the pilot hybrid systems. The report also benefited from initial contribution of Antonio Lopez Martinez (former energy specialist of ADB) and peer review by Lei Zhang, senior energy specialist, ADB. Jose Aguado would also like to acknowledge the collaboration of Daniel Álvaro, José Manuel Gonzalez, and Violeta Sánchez, who are graduate students at the University of Malaga in Spain. 


\section{ABBREVIATIONS}

$\begin{array}{ll}\text { AC } & \text { alternating current } \\ \text { ADB } & \text { Asian Development Bank } \\ \text { DC } & \text { direct current } \\ \text { kW } & \text { kilowatt } \\ \text { kWh } & \text { kilowatt-hour } \\ \text { LCOE } & \text { levelized cost of energy } \\ \text { O\&M } & \text { operation and maintenance } \\ \text { OPEX } & \text { operational expenditures } \\ \text { SOC } & \text { state of charge } \\ \text { PV } & \text { photovoltaic }\end{array}$




\section{INTRODUCTION}

\subsection{Background and Context}

1. Most electrical systems in remote rural areas or small islands which are isolated from the large main electrical grids still rely on diesel generator sets to produce electricity. Diesel generators are cheap to install and are reliable, but their operation cost associated with fuel consumption results in the high cost of electricity in such islanded systems. Moreover, the cost of energy in these communities is totally vulnerable to market fluctuations of the price of fuel. In less-developed areas, this can mean periods of economical incapability to serve the electrical demand. In view of this, it seems logical to try substituting part of the fuel-based generation with the renewable energy, such as solar or wind energy, whose primary sources come at no cost and that do not pollute the environment. On the other hand, solar and wind energy are intermittent and are not completely predictable. Moreover, photovoltaic arrays and wind turbines have high initial investment costs. With today's prices for the different generation and storage technologies, a compromise between (a) the controllable but highoperating cost diesel generators and (b) the high-investment cost renewable energy sources and storage elements, seems to be the most economical solution in most cases.

2. Hybrid isolated electrical systems, commonly referred to as stand-alone microgrids or minigrids, are systems that combine diesel generators with renewable energy sources such as solar photovoltaic panels and wind turbines, and energy storage elements such as batteries, flywheels, or pumped hydro installations.

3. Determining the power generation mix and electric battery storage elements that result into the lowest cost of energy, while at the same time meeting other constraints such as minimum renewable energy penetration, available initial capital or maximum annual $\mathrm{CO}_{2}$ emissions, is a complex problem. It depends on many factors such as, among others, the electric demand profile, solar and wind resources, price of fuel, or the available space.

\subsection{About this Microsoft Excel-Based Workbook}

4. The purpose of this workbook is to assist in finding the most cost-effective configurations for a hybrid stand-alone system. To do this, the user introduces a search space of possible components, including diesel generators, wind turbines, solar photovoltaic installations, and battery storage along with technical and economic inputs for each element.

5. This Microsoft Excel-based workbook simulates operation for each possible configuration of the system that results from the search space of components introduced by the user. For this purpose, hourly time series are generated for electric demand, solar radiation, and wind speed based on data introduced by the user. 
6. A Microsoft Excel macro lists all feasible combinations results over the lifetime of the project (typically between 20 and 25 years) such that the user can easily sort them by their net present cost. Many different results, such as costs detailed by component, annual cash flows, generation statistics, annual expected emissions and others, are automatically calculated for each feasible solution.

7. The interface is simple and straightforward; inputs for each component are separated in different tabs while results and graphs are presented in tabs as well. 


\section{INPUT DATA FOR THE WORKBOOK}

8. This section shows the required inputs to optimize a hybrid system design using the Microsoft Excel-based workbook. To introduce data, the user needs to go through the tabs filling the purple cells.

\subsection{Project Data}

The following data specified in Table 1 related to the project have to be introduced.

Table 1: Project Data

\begin{tabular}{ll}
\hline Project Data & \multicolumn{1}{c}{ Operation Constraints } \\
\hline Project lifetime & Wind spinning reserve coefficient \\
Real interest rate & Photovoltaic spinning reserve coefficient \\
& Load spinning reserve coefficient \\
\hline
\end{tabular}

Source: José Aguado (ADB consultant, Effergy Energia).

9. These parameters are defined as follows:

(i) Project lifetime (years). This is defined as length of time over which the costs of the system are calculated. Typical values range from 20 years to 30 years. Salvage value of components is considered at the end of the last year.

(ii) Real interest rate (\%). The real interest rate is used to discount annual cash flows to the present value of money to calculate the net present cost of the project. The real interest rate aims to discount the effect of inflation from the nominal interest rate (the interest rate at which the project is financed). By using the real interest rate, the net present costs can be considered constant monetary units. The real interest rate is computed as follows:

$$
\operatorname{rir}=\frac{n i r-i n f}{1+i n f}
$$

where

$$
\begin{aligned}
& \text { rir }=\text { real interest rate } \\
& \text { nir }=\text { nominal interest rate } \\
& \text { inf }=\text { inflation rate }
\end{aligned}
$$


(iii) Spinning reserve coefficient. Spinning reserve is the margin that allows to immediately increase power output which running diesel generator sets must have at all times in order to quickly compensate for changes in demand and/or intermittent renewable generation. This margin can be computed as a percentage of the power demand, and solar and wind generation for each time step. For example, if the wind spinning reserve coefficient is $15 \%$, this means that synchronized generator sets must be able to increase their power output in $15 \%$ of the wind power output for that time step for the spinning reserve requirement to be fulfilled. Batteries are also considered to provide spinning reserve. The amount of spinning reserve they provide in each time step is equal to the maximum amount of power that can be discharged by them during that time step.

The available spinning reserve for each time step is thus

$$
\text { Available } S P=\sum_{i} u_{d g_{i}} \cdot\left(P_{d g_{i}}^{\text {rated }}-P_{d g_{i}}\right)+P_{\text {discharge }}^{\text {max }}
$$

where

$u_{d g_{i}}=1$ if diesel generator set $i$ is running during that time step, 0 otherwise

$P_{d g_{i}}^{\text {rated }}=$ Rated power output of diesel genset $i(k W)$

$P_{d g_{i}}=$ Output power of diesel genset $i$ during that time step $(k W)$

$P_{\text {discharge }}^{\max }=$ Maximum power that can be discharged from the battery $(k W)$

The required spinning reserve, Required $S P([k W)]$, during each time step is computed as a percentage of the load and renewable generation as follows:

$$
\text { Required } S P=\frac{1}{100}\left(\% S P_{P V} \cdot P_{P V}+\% S P_{W T} \cdot P_{W T}+\% S P_{L} \cdot P_{L}\right)
$$

where

$\% S P_{P V}=$ Spinning reserve coefficient for photovoltaic plants

$\% S P_{W T}=$ Spinning reserve coefficients for wind turbines

$\% S P_{L}=$ Spinning reserve coefficients for demand

$P_{P V}=$ Average power generated by photovoltaic plants $(k W)$

$P_{W T}=$ Average power generated by wind turbines $(k W)$

$P_{L}=$ Average power demand $(k W)$

10. An example of project input data in the workbook is provided in Figure 1. 
Figure 1: Project Data

\section{Project Date}

Project Lifetime

25 years

Real Interest Rate

$4,000 \%$

\section{Operation Constraints}

Wind Spinning Reserve Coefficient

PV Spinning Reserve Coefficient

Load Spinning Reserve Coefficient

\begin{tabular}{l}
$0,000 \%$ \\
\hline $0,000 \%$ \\
\hline $0,000 \%$
\end{tabular}

$\mathrm{PV}=$ photovoltaic.

Source: José Aguado (ADB consultant, Effergy Energia).

\subsection{Load Demand}

11. To model electricity consumption through the year, the user has two options. The first option is to introduce 720 values ( 30 days hour by hour) if they are available from previous measures. The second option is to generate a synthetic time series based on a few inputs.

12. To generate an hourly time series that models 1 year for the electrical demand, the user needs to introduce the following inputs:

- Baseline demand profile. This consists of hourly values of demand for a typical day. This data is used as a baseline profile of the daily electricity consumption curve to generate the 720 values that model demand during the year.

- Average load for each month $(\mathrm{kW})$. This value represents the average value of the load for each month.

- Two random variability coefficients. The higher these coefficients, the more demand will differ from the baseline profile. Usually, the lower the number of consumers the larger deviations that can be expected from the expected profile:

- Day-to-day (\%)

- Hour-to-hour (\%)

Figure 2 provides an example of load inputs in the workbook. 


\begin{tabular}{|c|c|c|c|c|c|}
\hline \multicolumn{6}{|c|}{ Figure 2: Load Input Sheet } \\
\hline \multicolumn{6}{|c|}{ LOAD $\quad$ D } \\
\hline & End time & $\begin{array}{c}\text { Demand } \\
\text { (kW) }\end{array}$ & Aver & rage Load I & \\
\hline & 1:00 & 3,33 & & & \\
\hline & 2:00 & 3,45 & January & 26,0377 & \\
\hline & 3:00 & 3,68 & February & 24,447 & \\
\hline & 4:00 & 4,25 & March & 25,8477 & \\
\hline & 5:00 & 5,98 & April & 25,463 & \\
\hline & 6:00 & 11,845 & May & 24,9931 & \\
\hline & $7: 00$ & 9,315 & June & 26,0056 & \\
\hline & 8:00 & 5,175 & July & 25,6883 & \\
\hline & 9:00 & 3,22 & August & 26,6262 & \\
\hline & 10:00 & 3,22 & September & 25,5628 & \\
\hline & 11:00 & 5,865 & October & 25,2451 & \\
\hline & 12:00 & 7,015 & November & 25,3982 & \\
\hline & 13:00 & 5,175 & December & 25,2513 & \\
\hline & 14:00 & 4,255 & & & \\
\hline & 15:00 & 3,335 & & & \\
\hline & 16:00 & 3,335 & & & \\
\hline & 17:00 & 3,795 & Ran & dom variab & \\
\hline & 18:00 & 7,13 & & & \\
\hline & 19:00 & 20,355 & Day to Day & 25 & $\%$ \\
\hline & 20:00 & 25,3 & Time-step to time-step & 15 & $\%$ \\
\hline & $21: 00$ & 21,39 & & & \\
\hline & 22:00 & 12,65 & Peak load & 34,46333 & $\mathrm{~kW}$ \\
\hline & 23:00 & 10,45 & & & \\
\hline & 0:00 & 5,175 & & & \\
\hline kW = kilowatt. & & & & & \\
\hline Source: José Ag & $\circ(A D B C c$ & onsultant, $\mathrm{E}$ & rgy Energia). & & \\
\hline
\end{tabular}

\subsection{Diesel Generators}

13. The input parameters for the diesel generator sets are defined in Table 2 .

Table 2: Diesel Generators Input Data

\begin{tabular}{ll}
\hline Technical & Economic \\
\hline Rated Output & Diesel Cost \\
\hline Minimum load & Capital cost \\
Fuel consumption curve $a \cdot P+b$ & Replacement cost \\
& O\&M Cost \\
& Lifetime \\
\hline
\end{tabular}

$O \& M=$ operation and maintenance

Source: José Aguado (ADB Consultant, Effergy Energia). 
14. These parameters are defined as follows:

- Rated output (kW). The nameplate power of the diesel generator.

- Minimum load (\%). The minimum allowable power output for each generator set when it is synchronized. This parameter is considered because prolonged periods of running at loads below the minimum recommended by the manufacturers will result in poor combustion inside the cylinder due to abnormally low temperature and pressure. This, in turn, will drastically reduce the lifetime of the generator.

- Fuel consumption curve. The fuel consumption curve is modeled as a linear function of power output by using "a" and "b" scalars:

- a (liter per kilowatt-hour [l/kWh]). It represents a slope of the fuel consumption curve, and is the marginal fuel consumption of increasing the power output in $1 \mathrm{~kW}$ during 1 hour.

- b (liter per hour $[\mathrm{l} / \mathrm{h}]$ ). This is a Y-axis intercept of the fuel consumption curve, or idle fuel consumption.

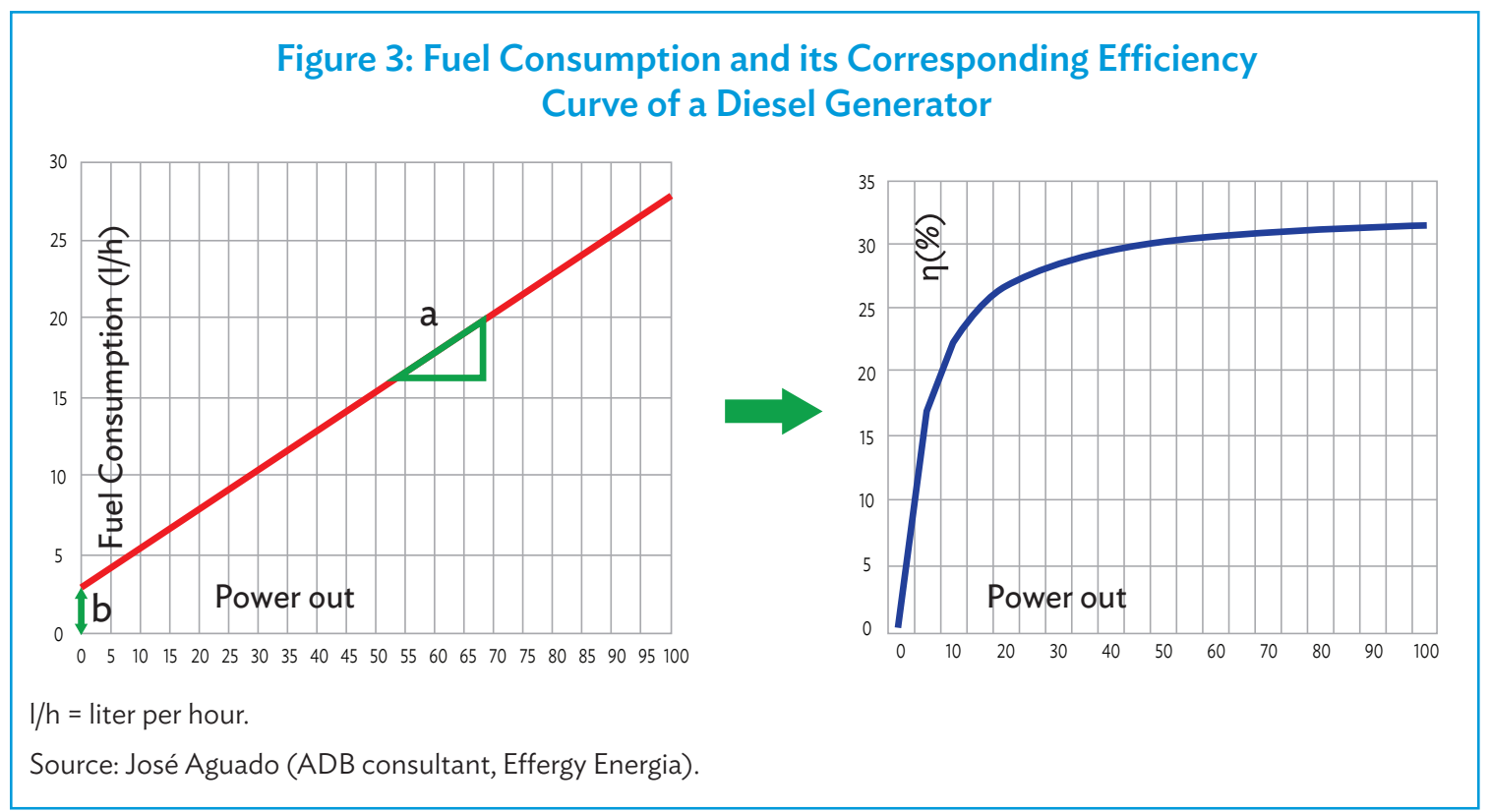

- Diesel cost (\$/I). Cost of 1 liter of fuel.

- Capital cost $(\$ / I)$. Initial investment cost of the diesel generator set. It should include the cost of the generator itself and other costs that derive from installing this generator for the first time (all ancillary equipment such as controllers, wires, etc.).

- Replacement cost $(\$ / I)$. Cost of replacing a diesel generator set once it has reached the end of its life span. It will usually be lower than the capital cost because probably not all components will need to be replaced. 
- Operation and maintenance cost $(\$ / \mathrm{h} \cdot \mathrm{kW})$. This represents average estimated operation and maintenance costs per operating hour and kilowatt of rated power.

- Lifetime (hours). This is the total number of hours that a diesel generator set can operate.

15. Figure 4 provides an example of diesel generator inputs in the workbook.

Figure 4: Diesel Generators Input Data

\section{DIESEL GENERATOR}

\section{4}
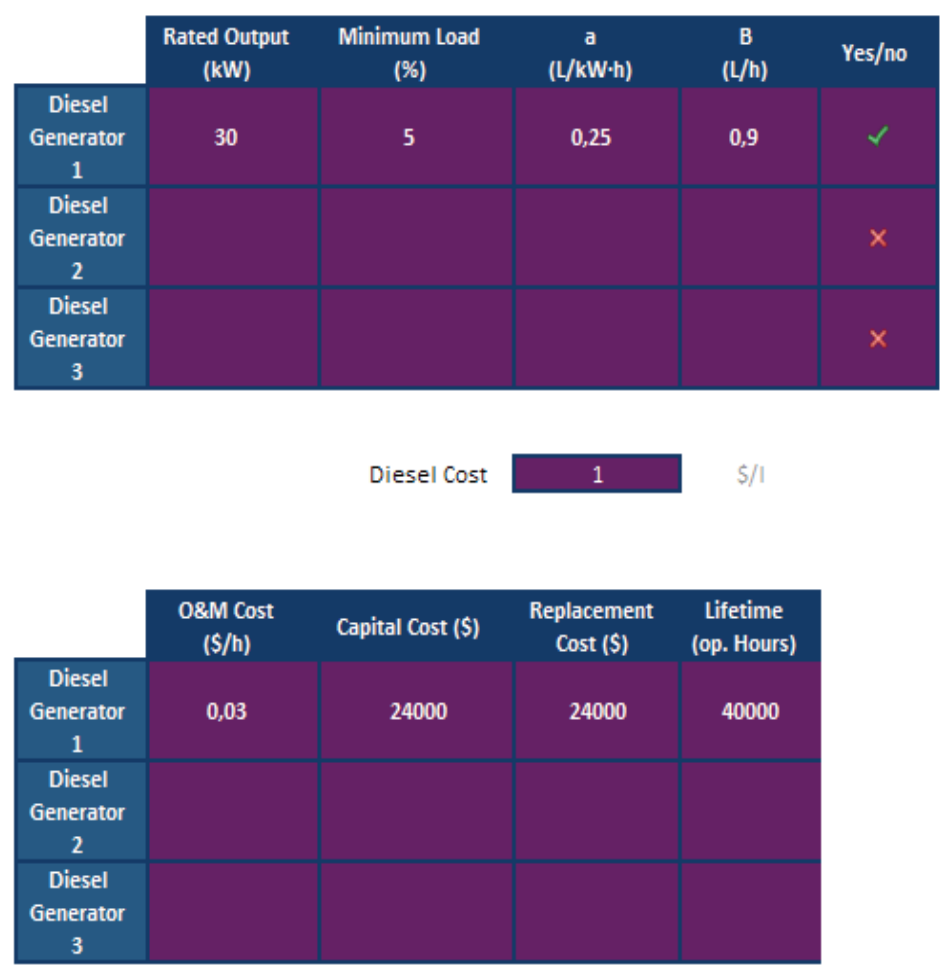

$\mathrm{kW}=$ kilowatt, $\mathrm{l} / \mathrm{h}=$ liters per hour, $\mathrm{l} / \mathrm{kWh}=$ liters per kilowatt-hour. Source: José Aguado (ADB consultant, Effergy Energia). 


\subsection{Wind Resource}

16. To compute the average output power of wind turbines, an hourly wind speed series for 1 year is required. The user can either introduce the 720 values or generate a synthetic time series based on a few inputs.

17. The input parameters for the wind resource are defined in Table 3.

Table 3: Wind Resource Input Data

\begin{tabular}{l}
\hline Monthly average wind speed \\
Autocorrelation coefficient \\
Weibull shape factor "k" \\
Anemometer height \\
\hline
\end{tabular}

Source: José Aguado (ADB consultant, Effergy Energia).

18. These parameters are defined as follows:

- Monthly average values $(\mathrm{m} / \mathrm{s})$. Average wind speed is in meters per second $(\mathrm{m} / \mathrm{s})$ for each month.

- Autocorrelation coefficient. This is represented by a number between 0.2 and 0.8 . This parameter is used to control the degree of randomness in the time series. The higher this parameter the more the value of wind speed depends on the value of the hour before.

- Weibull distribution shape factor. The distribution for wind speed probability most used to fit wind speed histograms is the Weibull distribution, although other distributions provide better fittings in areas where wind speed is rather anisotropic. Weibull distribution probability density function is defined as follows:

$$
p(u)=\frac{k}{A} \cdot\left(\frac{u}{A}\right)^{k-1} \cdot e^{\left(-\frac{u}{A}\right)^{k}}
$$

where

$$
\begin{aligned}
& p(u)=\text { Probability of wind speed } b " u " \\
& A=\text { Average wind speed }\left(\frac{m}{s}\right) \\
& k=\text { Shape factor }
\end{aligned}
$$


19. For typical wind distributions, $k$ is in the range of $2-3$. Lower values of $k$ indicate a flatter distribution, while increasing $k$ makes the distribution peak around wind speeds corresponding to the mode value which is given as follows:

$$
\text { mode }=A \cdot \frac{(k-1)^{\frac{1}{k}}}{k}
$$

20. If the range of possible wind speeds is divided in equal length intervals, the interval centered on the mode value has the higher probability. In other words, the mode value represents the most frequent value for wind speed. Thus, a wind turbine suitable for that area should perform well with wind speeds around that value. Weibull probability distribution for different values of $k$ (left) and $A$ (right) is presented under Figure 5.

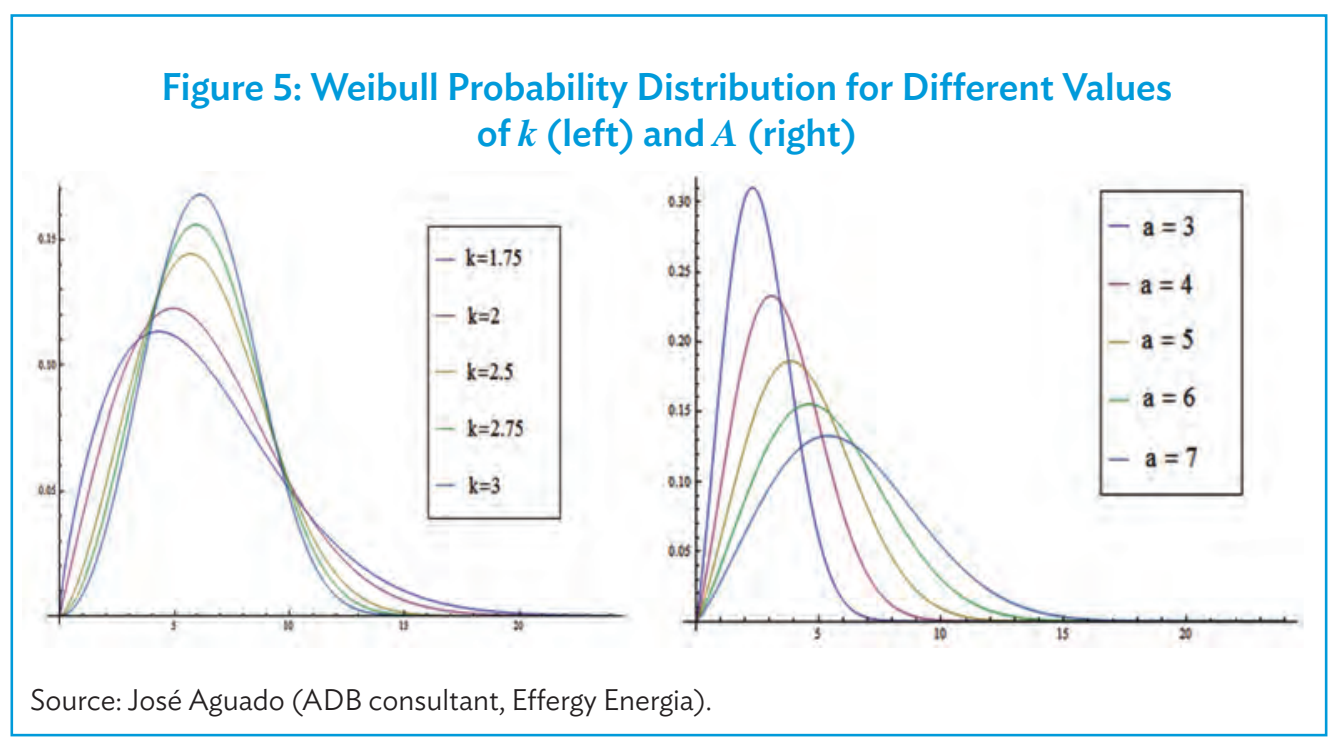

- Anemometer height $(m)$. Wind speed values entered by the user correspond to measures at a given height that might not be that of the wind turbines in the search space. Wind speed tends to increase with height. The logarithmic wind profile is used to correct wind speed measures with varying height is as follows:

$$
\frac{u_{w t}}{u_{\text {anem }}}=\ln \left(\frac{h_{w t} / h_{0}}{h_{\text {anem }} / h_{0}}\right)
$$

where

$u_{w t} \mid u_{\text {anem }}=$ wind speed at the height of the wind turbine hub $\mid$ anemometer $\left[\frac{\mathrm{m}}{\mathrm{s}}\right]$

$h_{w t} \mid h_{\text {anem }}=$ height of the wind turbine hub | anemometer $[\mathrm{m}]$

$h_{0}=$ Surface roughness length $[\mathrm{m}]$ 
21. Figure 6 provides an example of wind resource inputs in the workbook.

Figure 6: Wind Resource Input Data

Average Wind Speed $(\mathrm{m} / \mathrm{s})$

\begin{tabular}{|c|c|c|c|c|}
\hline January & 4,98 & \multirow{2}{*}{\multicolumn{3}{|c|}{ Probability Density Function }} \\
\hline February & 5,082 & & & \\
\hline March & 4,149 & 0,18 & & \\
\hline April & 4,364 & 0,16 & & \\
\hline May & 7,553 & 0,14 & & \\
\hline June & 8,3 & 0,12 & & \\
\hline July & 8,15 & 0,1 & & \\
\hline August & 7,3 & $\begin{array}{l}0,08 \\
0,06\end{array}$ & & \\
\hline September & 6,1 & 0,04 & - & \\
\hline October & 4,9 & 0,02 & & \\
\hline November & 4,839 & 0 & $\ldots$ & 11111. \\
\hline December & 6,3 & & $\begin{array}{lllll}0 & 1 & 2 & 3 & 4\end{array}$ & $\begin{array}{lllllllllllll}5 & 6 & 7 & 8 & 9 & 10 & 11 & 12 & 13 & 14 & 15 & 16 & 17\end{array}$ \\
\hline
\end{tabular}

\begin{tabular}{|ll|}
\hline \multicolumn{1}{|c|}{ Surface Roughness Length } & $\mathrm{m}$ \\
- Very smooth, ice or mud & 0,00001 \\
- Calm open sea & 0,0002 \\
- Blown sea & 0,0005 \\
- Snow surface & 0,003 \\
- Lawn grass & 0,008 \\
- Rough pasture & 0,01 \\
- Fallow field & 0,03 \\
- Crops & 0,05 \\
- Few trees & 0,1 \\
- Many trees, few buildings & 0,25 \\
- Forest and woodlands & 0,5 \\
- Suburbs & 1,5 \\
- City center, tall buildings & 3 \\
& \\
\hline
\end{tabular}

$\mathrm{m} / \mathrm{s}=$ meter per second

Source: José Aguado (ADB consultant, Effergy Energia). 


\subsection{Wind Turbines}

22. The following input data (Table 4) are required for each type of wind turbine in the search space.

Table 4: Wind Turbines Data

\begin{tabular}{ll}
\hline Technical & Economic \\
\hline Search space & Lifetime \\
\hline Power curve & Capital cost \\
Turbine hub height & Replacement cost \\
Surface roughness length & O\&M cost \\
\hline
\end{tabular}

O\&M = operation and maintenance.

Source: José Aguado (ADB consultant, Effergy Energia).

- Search space. This represents the number of wind turbine units to consider during the simulation process.

- Power curve of a wind turbine. This represents the final (after the necessary conversions) electrical power output as a function of wind speed. The user can introduce a table of power output $(\mathrm{kW})$ versus wind speed $(\mathrm{m} / \mathrm{s})$ or select one of the already built-in turbine models. In Figure 7 , it can be observed at typical wind turbine power curve versus wind speed.

Figure 7: Wind Turbine Power Curve

POWER CURVE T1

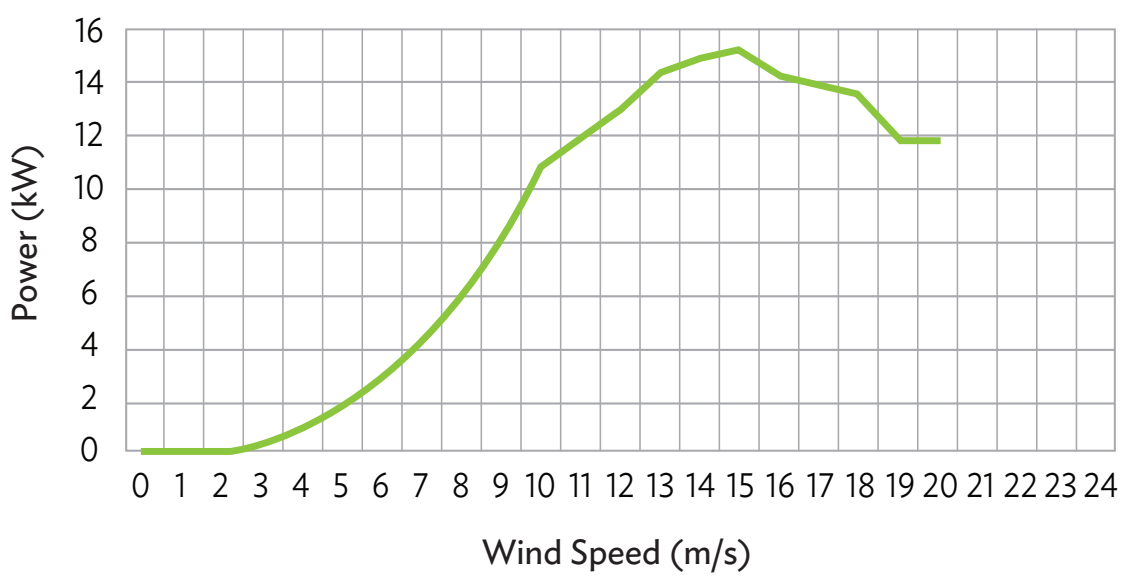

$\mathrm{kW}=$ kilowatt, $\mathrm{m} / \mathrm{s}=$ meter per second.

Source: José Aguado (ADB consultant, Effergy Energia). 
- Turbine hub height $(m)$. Height of the hub of the wind turbine above ground level.

- Surface roughness length $(m)$. Surface roughness is the parameter used in the logarithmic wind profile to model the average height of ground-level obstacles. The higher this value, the more obstacles slow down wind at near-ground levels. This value depends on the kind of surface. A table with typical values taken from [4] is shown in the spreadsheet as it can be seen in Figure 8.

- Lifetime [years]. For wind turbines, life span is considered independent of the operation.

- Capital cost (\$/unit). This represents cost of installing one wind turbine for the first time. It includes the cost of the turbine itself plus all other ancillary equipment.

- Replacement cost (\$/unit). This represents cost of replacing the necessary elements of the turbine at the end of its life span.

- Operation and maintenance costs (\$/unit year). This represents estimated average operation and maintenance costs per year and turbine.

23. Figure 8 provides an example of wind turbine inputs in the workbook.

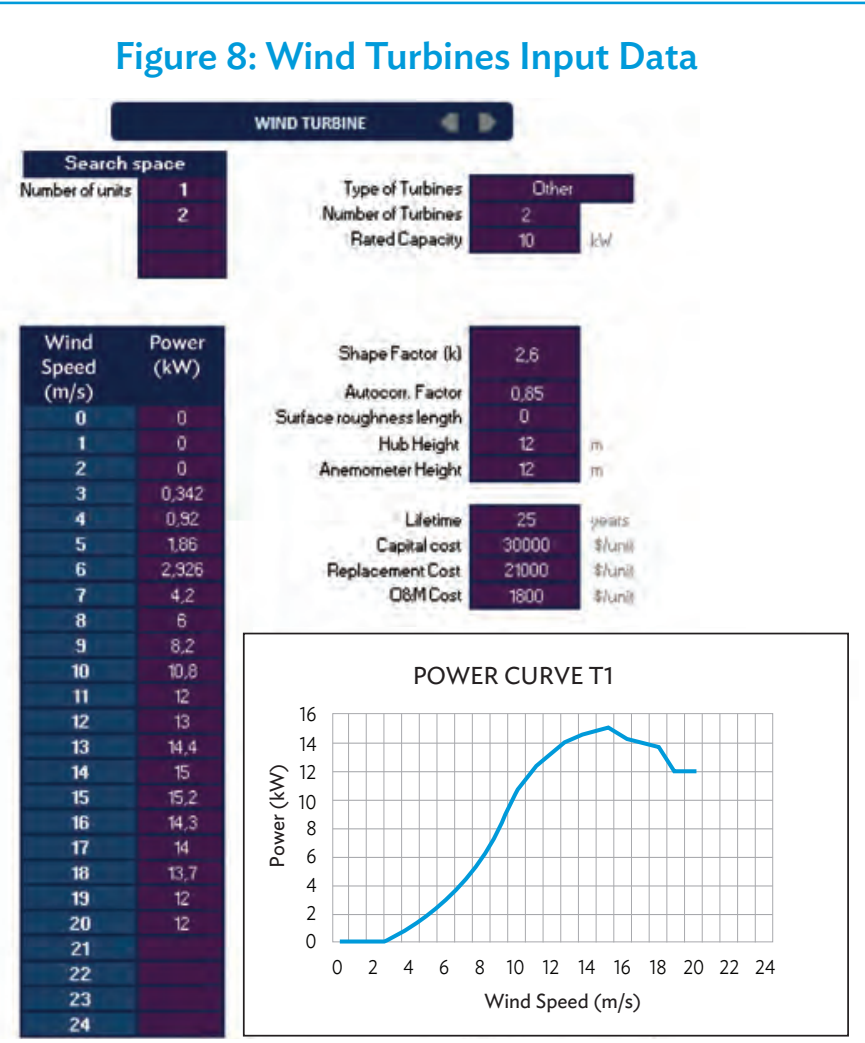

$\mathrm{kW}=$ kilowatt $\mathrm{m} / \mathrm{s}=$ meter per second, $\mathrm{O} \& \mathrm{M}=$ operation and maintenance.

Source: José Aguado (ADB consultant, Effergy Energia). 


\subsection{Solar Resource}

24. To calculate power output of the different photovoltaic installations, 1 year of hourly values of incident horizontal radiation is required. The user can either introduce the 720 ( 24 hours by 30 days) values or generate a synthetic time series. To generate a synthetic time series for solar resource, extraterrestrial solar radiation is computed. Extraterrestrial radiation (solar radiation at the top of the atmosphere) is only a function of the location's coordinates and time of the year. A percentage of this radiation is filtered in the atmosphere, mostly by clouds. The fraction of extraterrestrial radiation that makes it to the ground is commonly referred to as "clearness index." From measured monthly average horizontal radiation values (which can be easily found in databases for most locations) and extraterrestrial radiation, an hourly correlated time series for clearness index can be generated to simulate cloudiness effect. This is done using a probability transformation method developed by Graham and Hollands [1]. The product of extraterrestrial radiation and clearness index for each hour of the year is the incident horizontal solar radiation, which is used to calculate power generated by photovoltaic installations.

25. The following input data (Table 5) are required for solar resource determination.

Table 5: Solar Resource Input Data

\begin{tabular}{l}
\hline Latitude \\
Longitude \\
UTC time zone \\
Monthly average daily horizontal radiation \\
\hline UTC = coordinated universal time. \\
Source: José Aguado (ADB consultant, Effergy Energia).
\end{tabular}

26. These parameters are defined as follows:

- Latitude (degree). Angular distance from the equator of the location. North Pole is +90 degrees and South Pole is -90 degrees.

- Longitude (degree). Longitude is the angular distance from the Prime Meridian, ranging from +180 degree eastward and -180 degree westward.

- UTC time zone. It is the coordinated universal time used to translate solar time into clock time.

- Monthly average daily solar radiation (kWh/day). This is the average daily radiation for each month.

27. Figure 9 provides an example of solar resource inputs in the workbook. 
Figure 9: Solar Resource Input Data

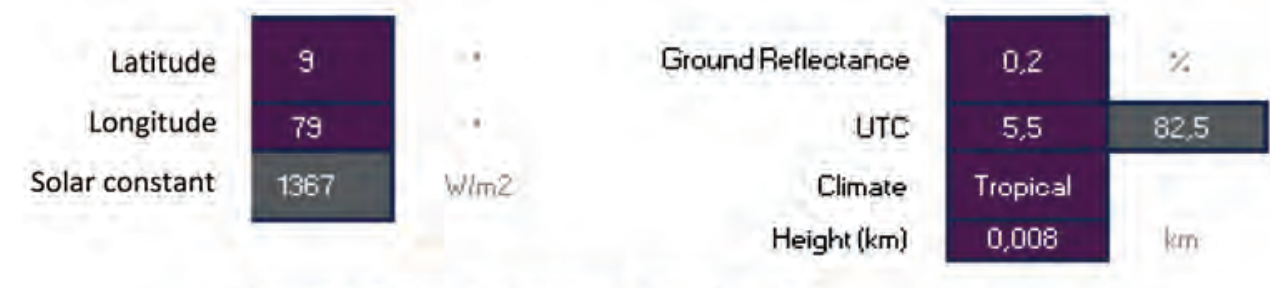

Average Solar Radiation (kW/m2/day)

\begin{tabular}{l|c|}
\cline { 2 - 2 } January & 4,502 \\
\hline February & 5,504 \\
March & 5,54 \\
April & 5,798 \\
May & 5,481 \\
June & 4,659 \\
July & 4,88 \\
August & 4,626 \\
September & 5,024 \\
Ootober & 4,561 \\
November & 4,278 \\
December & 3,925 \\
\hline
\end{tabular}

$\mathrm{km}=$ kilometer, $\mathrm{kW}=$ kilowatt, $\mathrm{UTC}=$ coordinated universal time, $\mathrm{W} / \mathrm{m}^{2}=$ watt per square meter Source: José Aguado (ADB consultant, Effergy Energia).

28. Figure 10 provides an example of average solar radiation and clearness index for a particular location.

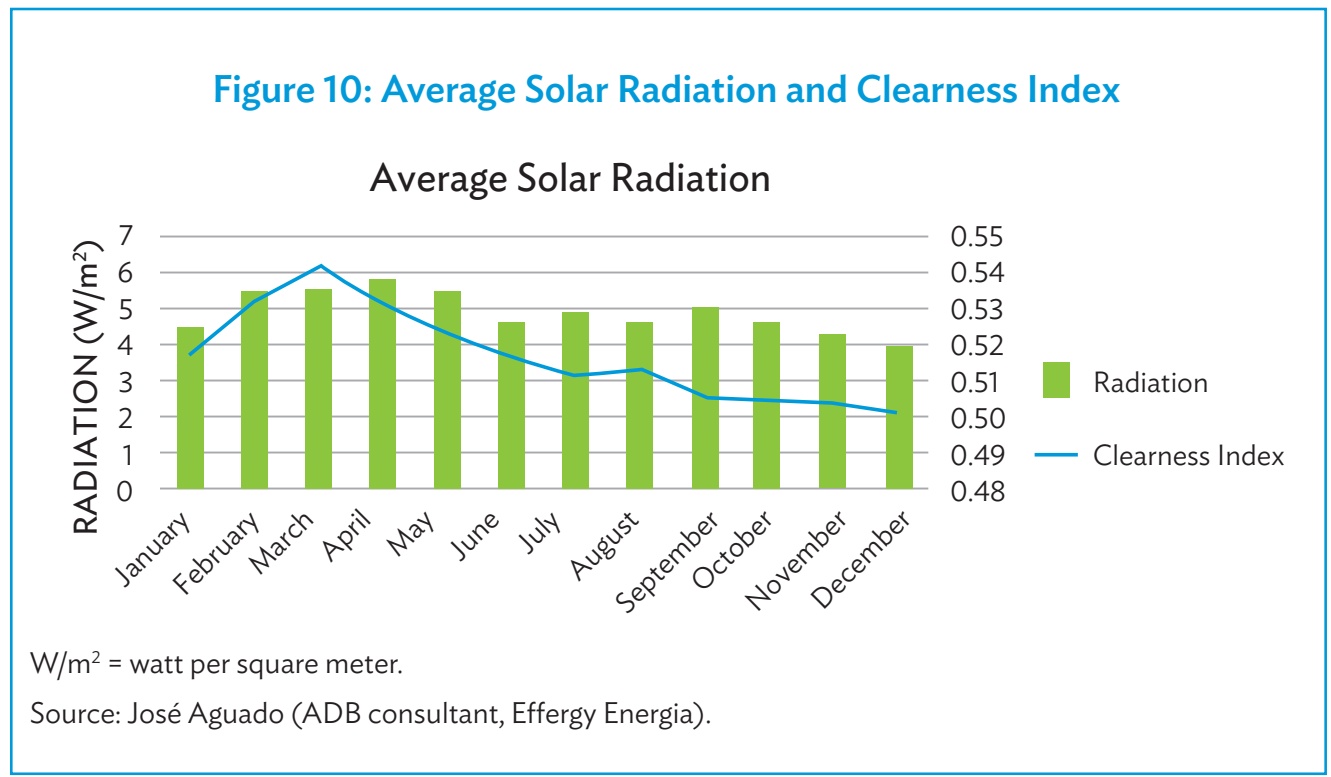




\subsection{Photovoltaic Arrays}

29. Different solar photovoltaic installations can be introduced in the search space with different costs, efficiency, and orientations. The following input data (Table 6) are required for determination of photovoltaic installations.

Table 6: Photovoltaic Installations Input Data

\begin{tabular}{ll}
\hline Technical & Economic \\
\hline Search space (units) & Lifetime \\
\hline Rated capacity per unit & Capital cost \\
\hline Efficiency & Replacement cost \\
\hline Tilt angle & O\&M cost \\
\hline Azimuth angle & \\
\hline Ground reflectance & \\
\hline
\end{tabular}

O\&M = operation and maintenance.

Source: José Aguado (ADB consultant, Effergy Energia).

30. These parameters are defined as follows:

- Rated capacity per unit (kWp). This is the nominal power of each photovoltaic unit in peak $\mathrm{kWs}$, ideally the maximum power output when the radiation striking the panel is $1 \mathrm{~kW} / \mathrm{m} 2$ and temperature of the panel is $25^{\circ} \mathrm{C}$.

- Efficiency (\%). This coefficient accounts for the losses in direct current (DC)/ alternating current (AC) conversion, wires, and temperature and dust effects. The power output of a photovoltaic installation during each time step is computed as follows:

$$
\circ \quad P_{P V}[k W]=N_{\text {units }} \cdot \text { Efficiency } \text { f }_{P V} \cdot P_{P V}^{\text {rated }}[k W p] \cdot \frac{\text { Incident Radiation }\left[\frac{\mathrm{kW}}{\mathrm{m}^{2}}\right]}{1\left[\frac{\mathrm{kW}}{\mathrm{m}^{2}}\right]}
$$

- Tilt angle (degree). This reflects horizontal inclination of the panels.

- Azimuth angle (degree). This reflects the direction toward which the panels face: 0 degree is south, 90 degrees is west, 180 degrees is north, and -90 degrees is east.

31. These definitions are further clarified in Figure 11. 
Figure 11: Photovoltaic Panels Angles

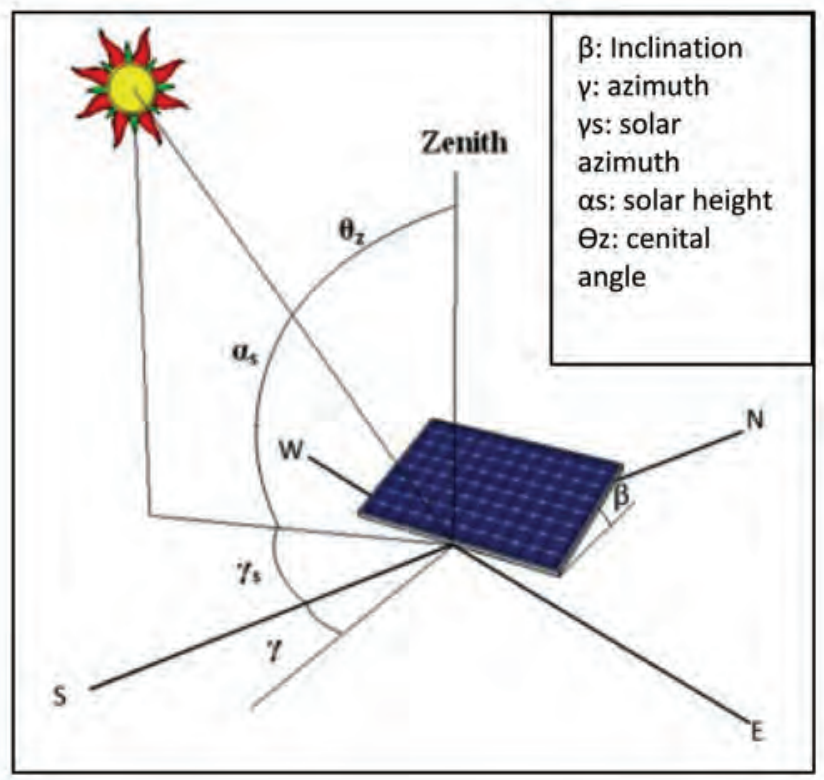

Source: [2] William Surles Solar Angles and Tracking Systems. Online available at https://www.teachengineering.org/lessons/view/cub_pveff_lesson01

- Ground reflectance (\%). Also called albedo, it is the percentage of solar incident radiation of the ground that is reflected. It is used to calculate a part (not very significant) of the incident radiation on tilted panels.

- Lifetime (years). Life span of a photovoltaic installation is considered independent of the operation. Photovoltaic panels usually have a guaranteed life span of over 25 years, but other components of the installation, such as the inverters, might have a shorter life span.

- Capital cost (\$/kilowatt peak [kWp]). Cost of installing $1 \mathrm{kWp}$ of photovoltaic panels for the first time. It should include the cost of the photovoltaic panel itself plus all the other ancillary equipment.

- Replacement cost $(\$ / \mathrm{kWp})$. This is cost of replacing all the necessary elements of the photovoltaic panel at the end of its lifetime.

- Operation and maintenance costs $(\$ / \mathrm{kWp}$ year). This reflects estimated average operation and maintenance costs per year and kilowatt peak of a photovoltaic panel.

32. Figure 12 provides an example of photovoltaic panel inputs in the workbook. 


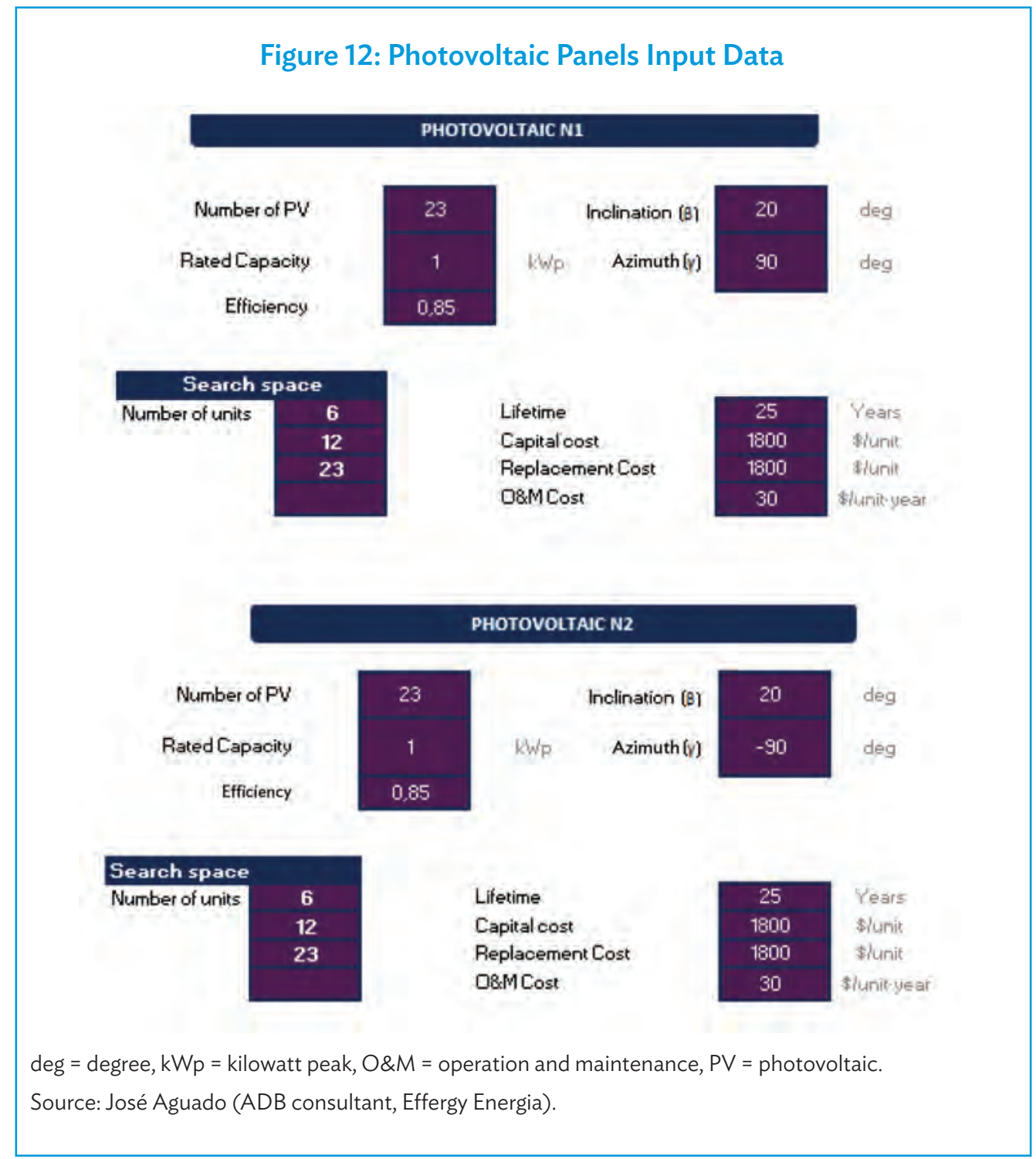

\subsection{Electric Battery Storage System}

33. The electric battery storage is modeled using a simplified version of the kinetic battery model developed by Manwell and McGowan [3][4]. This model accounts for rate effect in effective capacity and recovery effect, which have an important impact on some types of batteries (mainly on lead acid-based technology batteries). In this model, the battery's charge is distributed over two wells: the available-charge well and the bounded-charge well.

34. The available-charge well provides current directly to the load where $\mathbf{i}(\boldsymbol{t})$ is the current as a function of time $t$ and $\mathbf{i}(\boldsymbol{t})>\mathbf{0}$ means discharge, whereas the bound-charge well provides current only to the available-charge well. The rate at which charge flows between the wells depends on the height difference between the two wells and on a parameter $\boldsymbol{k}$. A fraction " $c$ " of the total capacity is put in the available-charge well, and the remaining " $(1-c)$ " in the bounded-charge well. 
35. The height (capacities) of the two wells are given by $\boldsymbol{h}_{\mathbf{1}}=\boldsymbol{q}_{\mathbf{1}} \mathrm{c}$ and $\boldsymbol{h}_{\mathbf{2}}=\boldsymbol{q}_{\mathbf{2}}(\mathbf{1}-\boldsymbol{c}$ ) where $\boldsymbol{h}_{1}$ and $\boldsymbol{h}_{2}$ are the height for wells 1 and 2, respectively, and $\boldsymbol{q}_{\mathbf{1}}$ and $\boldsymbol{q}_{\mathbf{2}}$ the charges for wells 1 and 2 , respectively. The change of the charge in both wells is given by the following system of differential equations:

$$
\begin{gathered}
\frac{d q_{1}}{d t}=-i(t)+k\left(h_{2}-h_{1}\right) \\
\frac{d q_{2}}{d t}=-k\left(h_{2}-h_{1}\right)
\end{gathered}
$$

Figure13: Kinetic Battery Model

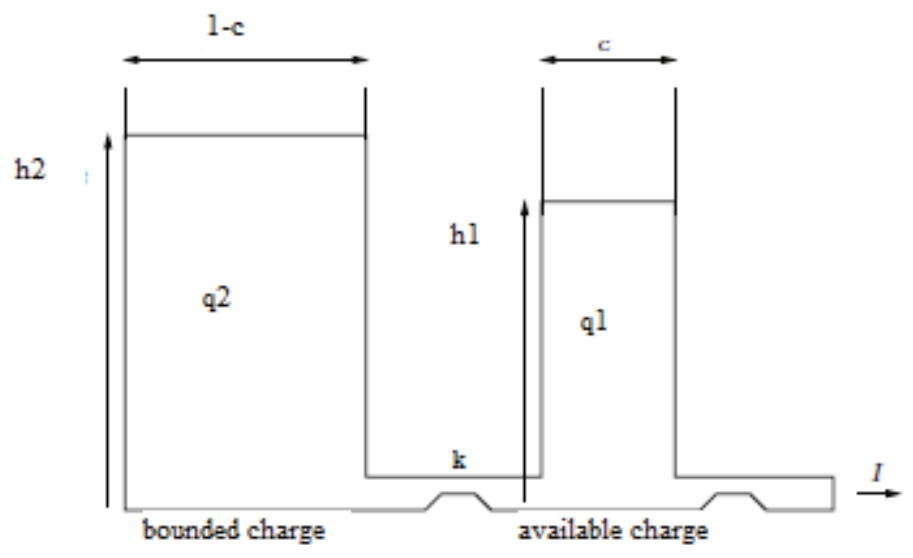

Source: J. Manwell and J. McGowan. 1994. Extension of the Kinetic Battery Model for Wind/Hybrid Power Systems. In Proceedings of the 5th European Wind Energy Association Conference (EWEC'94). pp. 284-289.

36. The real capacity of the battery at a given constant discharge current $\boldsymbol{I}$ is modeled by the following relation:

$$
q_{\max }(I)=\frac{q_{\max } k c T}{1-e^{-k T}+c\left(k T-1+e^{-k T}\right)}
$$

where

- I is the charge or discharge current (ampere).

- $\boldsymbol{T}$ is the charge or discharge time, defined by $T=\frac{q \max (I)}{I}$, (hour).

- $\boldsymbol{q}_{\max }$ the maximum capacity (at infinitesimal current) (ampere-hour).

- $\boldsymbol{k}$ is the rate constant $\left(\boldsymbol{h}^{-1}\right)$.

- $\boldsymbol{c}$ is the ratio of available charge capacity to total capacity. 
37. The available and bounded capacity and state of charge of the battery bank are computed as follows:

$$
\begin{gathered}
S O C_{t}=\frac{Q_{a}^{t}+Q_{b}^{t}}{\text { capacity }} \\
Q_{a}^{t}=Q_{a}^{t-1} e^{-k^{\prime} \Delta t}+ \\
+\frac{\left(\left(Q_{a}^{t-1}+Q_{b}^{t-1}\right) \cdot k^{\prime} c-\frac{P_{\text {disch }}^{t}}{\eta_{\text {disch }}}+\eta_{c h} P_{c h}^{t}\right)\left(1-e^{-k^{\prime} \Delta t}\right)}{k^{\prime}}- \\
-\frac{\left(-\frac{P_{\text {disch }}^{t}}{\eta_{\text {disch }}}+\eta_{c h} P_{c h}^{t}\right) \cdot c\left(k^{\prime} \Delta t-1+e^{-k^{\prime} \Delta t}\right)}{k^{\prime}} \\
Q_{b}^{t}=Q_{b}^{t-1}+\left(Q_{a}^{t-1}+Q_{b}^{t-1}\right) \cdot(1-c) \cdot\left(1-e^{k^{\prime} \Delta t}\right)- \\
-\frac{\left(\frac{P_{d i s c h}^{t}}{\eta_{\text {disch }}}-\eta_{c h} P_{c h}^{t}\right)(1-c)\left(k^{\prime} \Delta t-1+e^{-k^{\prime} \Delta t}\right)}{k^{\prime}}
\end{gathered}
$$

where

- $P_{\text {disch }}^{t}$ is power discharged from the battery.

- $P_{c h}^{t}$ is power charged in the battery.

- $\eta_{\text {disch }}$ is discharging efficiency.

- $\eta_{\text {disch }}$ is charging efficiency.

$k^{\prime}=\frac{k}{c(1-c)}$

38. The following input data (Table 7) are required for electric battery storage system determination. 
Table 7: Electric Battery Storage System Input Data

\begin{tabular}{ll}
\hline Technical & Economic \\
\hline Search space & Capital cost \\
\hline Capacity per battery & Replacement cost \\
\hline Capacity ratio & Operation and maintenance cost \\
\hline Rate constant & Battery wear cost \\
\hline Discharging efficiency & \\
\hline Charging efficiency & \\
\hline Lifetime throughput & \\
\hline Minimum SOC & \\
\hline Initial SOC & \\
\hline Capacity per battery & \\
\hline Inverter capital cost & \\
\hline Inverter replacement cost & \\
\hline
\end{tabular}

SOC = state of charge.

Source: José Aguado (ADB consultant, Effergy Energia).

39. These parameters are defined as follows:

- Search space represents the number of electric battery storage systems to be considered in the simulations.

- Capacity ratio $c$ is a parameter of the kinetic battery model.

- Rate constant $k[1 / \mathrm{h}]$ is a parameter of the kinetic battery model.

- Lifetime throughput (kWh) is the total amount of energy that can be cycled through the battery before it needs replacement. If lifetime throughput is reached before calendar lifetime, a replacement takes place in that year.

- Calendar lifetime (years) is maximum lifetime of the battery due to aging regardless of the operation.

- Initial state of charge (\%) is the initial state of charge at beginning of the year.

- Charging efficiency (\%) accounts for battery losses and rectifier efficiency in the charging process.

- Discharging efficiency accounts for battery losses and inverter efficiency in the charging process. 
- Capital cost (\$/unit) is cost of installing one battery for the first time. It should include the cost of the batteries plus all the other ancillary equipment such as control devices and monitoring systems.

- Replacement cost (\$/unit) is cost of replacing the batteries; it might be lower than capital costs if some elements, such as monitoring systems, containers, and other elements,, do not need to be replaced, and because of the expected decrease in prices.

- Operation and maintenance cost (\$/unit·year) is maintenance cost that is considered to be a fixed cost per unit and year.

40. Figure 14 provides an example of electric battery storage system inputs in the workbook.

Figure 14: Battery Bank Input Data

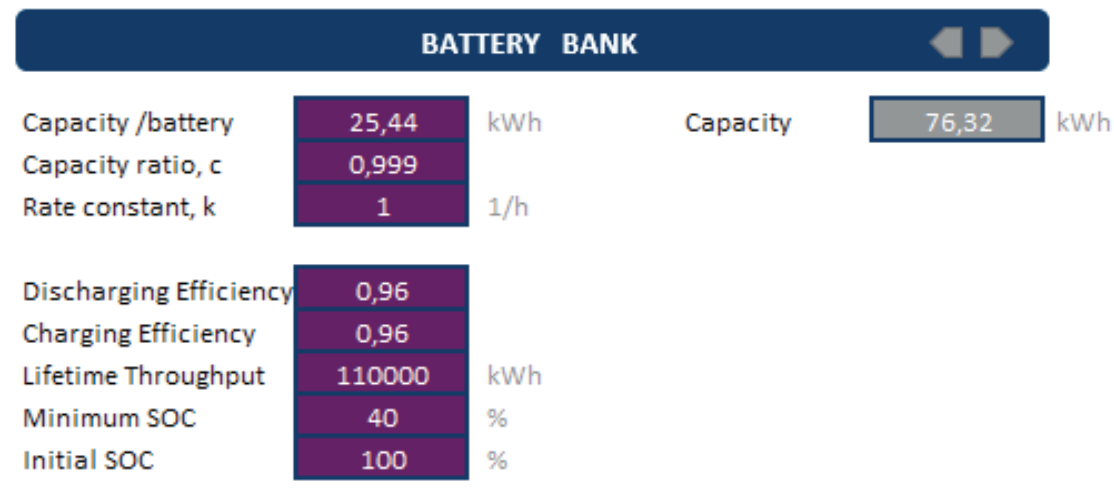

Operation Cost

Capital cost

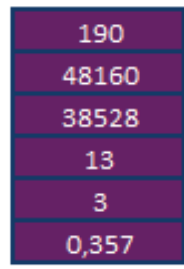

\$/year

Replacement Cost

Maximum lifetime

Number of batteries

Battery Wear Cost

0,357

\$/Battery

\$/battery

years

$\$ / \mathrm{kWh}$

\section{Search space}

Number of units

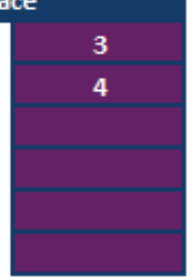

$\mathrm{h}=$ hour, $\mathrm{kWh}=$ kilowatt-hour, $\mathrm{SOC}=$ state of charge.

Source: José Aguado (ADB consultant, Effergy Energia). 
41. Similarly, for the power converter, the following parameters are defined as follows:

- Capacity (kW). This is the rated power of the power converter.

- Capital cost (\$/unit). This represents the cost of installing one power converter for the first time. It should include the cost of the converter plus all the other ancillary equipment such as control devices and monitoring systems.

- Replacement cost (\$/unit). This is the cost of replacing the power converter; it might be lower than capital costs if some elements, such as monitoring systems, containers, and other elements, do not need to be replaced, and because of the expected decrease in prices.

- Operation and maintenance cost (\$/unit·year). This represents the maintenance cost that is considered to be a fixed cost per unit and year.

42. Figure 15 provides an example of power converter system inputs in the workbook.

Figure15: Converter Input Data

\section{CONVERTER}

\begin{tabular}{|c|c|}
\hline Capacity & 100 \\
\hline Capital Cost & 61760 \\
\hline Replacement & 0 \\
\hline O\&M Cost & 500 \\
\hline
\end{tabular}

$\mathrm{kW}=$ kilowatt, $\mathrm{O} \& \mathrm{M}=$ operation and maintenance.

Source: José Aguado (ADB consultant, Effergy Energia). 



\section{WORKBOOK RESULTS}

\subsection{Operation}

43. Operation is simulated for each possible combination of elements in the search space. Some filters are applied in order to save time by not simulating operation for combinations that will not be able to fulfill all constraints.

44. Outputs of photovoltaic and wind generators are calculated using incident solar radiation and wind speed. Controllable elements (diesel generators and batteries) dispatch is calculated to optimize costs while fulfilling technical constraints.

45. Annual cash flows are calculated based on four different costs for each component:

- Capital cost. This is the cost of installing the component for the first time; capital costs are computed in the year 0 of the project.

- Replacement cost. This is cost of replacing a component at the end of its lifetime. When a component reaches its life span, its replacement cost is included in that year's cash flow.

- Operation and maintenance costs. Annual operation and maintenance costs are included in all annual cash flows.

- Fuel cost. This is annual cost of fuel consumed by diesel generators.

- Salvage value. The residual value of components at the end of the project life is calculated based on remaining life and replacement cost.

\subsection{Running the Macro}

46. Once the user has introduced a search space of different components for the hybrid system, clicking on "Generate Combination" (see Figure 16), creates a list with all feasible configurations of the system. Clicking on the "Evaluate" button simulates operation and creates a list of the most relevant results:

- Net present cost (\$). This is the sum of all cash flows discounted to present value of money using the real interest rate.

- Levelized cost of energy $(\$ / \mathrm{kWh})$. This is the average cost of energy during the whole life of the project.

- Initial investment cost (\$) 
- Operating costs (\$/year)

- Renewable energy penetration percentage (\%)

- Fuel consumption (1/year)

47. The user can then sort the different configurations of the hybrid system by any of these values using Microsoft Excel filters.

Figure 16: Running the Macro

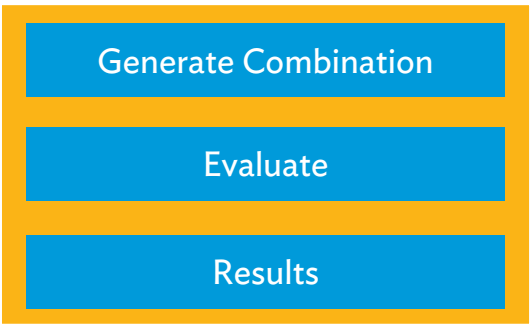

Source: José Aguado (ADB consultant, Effergy Energia).

48. To see detailed results for each configuration, such as a breakdown of costs by component and concept, generation statistics, or detailed operation of the system, the user simply selects the configuration and clicks on the "Results" button (see Figure 16).

49. An example of a typical cost summary result is given in Table 8 .

Table 8: Cost Summary

\begin{tabular}{|c|c|c|c|c|c|c|}
\hline & $\begin{array}{c}\text { Capital } \\
\text { [\$] }\end{array}$ & $\begin{array}{c}\text { Replacement } \\
\text { [\$] }\end{array}$ & O\&M (\$) & Fuel (\$) & $\begin{array}{c}\text { Salvage } \\
\text { [\$] }\end{array}$ & $\begin{array}{c}\text { Total } \\
\text { [\$] }\end{array}$ \\
\hline PV 1 & 41400 & 0 & 10779,235 & 0 & 0 & 52.179 .24 \\
\hline$P V Z$ & 41400 & 0 & 10779,235 & 0 & 0 & 52.179 .24 \\
\hline HT 1 & 60000 & 0 & 56239,488 & 0 & 0 & $116.239,49$ \\
\hline WT 2 & 0 & 0 & 0 & 0 & 0 & 0,00 \\
\hline DG 1 & 23076,92 & 12320,96 & 34657,584 & 158476,3 & $-4135,66$ & $224.396,11$ \\
\hline DG 2 & 0 & 0 & 0 & 0 & 0 & 0.00 \\
\hline DG 3 & 0 & 0 & 0 & 0 & 0 & 0,00 \\
\hline Battery & 144480 & 69416,76 & 8904,5856 & 0 & $-35975,1$ & $186.826,21$ \\
\hline Other & 61760 & 0 & 8123,4816 & 0 & 0 & $69.883,48$ \\
\hline \multirow[t]{2}{*}{ System } & $372.116,92$ & $81.737,71$ & $129.483,61$ & $158.476,30$ & $-40.110,79$ & $701.703,76$ \\
\hline & & & & & LCOE & 145,68 \\
\hline
\end{tabular}

\begin{tabular}{|c|c|}
\hline $\begin{array}{l}\text { Operating } \\
\text { cost }\end{array}$ & $5.179,34$ \\
$\begin{array}{l}\text { Ren. } \\
\text { Diesel }\end{array}$ & 0,62 \\
\hline
\end{tabular}

$D G=$ diesel generator, $L C O E=$ levelized cost of energy, $O \& M=$ operation and maintenance, $P V=$ photovoltaic, $W T=$ wind turbine.

Source: José Aguado (ADB consultant, Effergy Energia). 


\section{ANNEX: DETAILED CALCULATIONS}

1. In this Annex, the operations performed to obtain the results are explained in detail.

\subsection{Wind Speed Values}

2. Wind speed values are obtained from a Weibull probability distribution using random numbers. The hourly values are computed as follows:

$$
v=\lambda(-\ln |Z|)^{\frac{1}{K}}
$$

where

$$
\lambda=\frac{m w}{e^{\gamma\left(\ln \left(1+\frac{1}{K}\right)\right)}}
$$

and

- $\mathrm{Z}$ is a random number taken from a uniform distribution in [0,1].

- $\gamma$ is a gamma function.

- $K$ is a Weibull distribution shape parameter introduced by the user.

- $m w$ is monthly average wind speed introduced by the user.

3. This wind speed needs to be adjusted with the height of the hub using the log profile as follows:

$$
v_{h}=v * \frac{\ln \left(\frac{z_{\text {hub }}}{Z_{1}}\right)}{\ln \left(\frac{z_{\text {ane }}}{Z_{1}}\right)}
$$

where

$Z_{\text {hub }}$ is the hub height in meters.

$Z_{\text {ane }}$ is the anemometer height in meters.

$Z_{1}$ is the surface roughness length which can be taken from the table shown in the spreadsheet depending on the type of surface.

4. Wind power is obtained as a function of wind speed by interpolation in the power curve of the turbine and multiplying by the number of turbines. 


\subsection{Solar Radiation Values}

5. To obtain the solar radiation striking a tilted surface in each time step, the following operations are made:

(i) Calculate the declination for each time step:

$$
\delta=23.45^{\circ} * \sin \left(360^{\circ} \frac{284+n}{365}\right)
$$

where $n$ is the day of the year.

(ii) Time equation:

$$
\begin{array}{rl}
E & =3.85 *(0.000075+0.001868 * \cos B-0.032077 * \sin B-0.044615 * \cos 2 B-0.04089 \\
B & * 360^{\circ} \frac{n-1}{365}
\end{array}
$$

(iii) Solar time (ts):

$$
t s=t c+\frac{\text { longitude }}{\frac{15^{\circ}}{\text { hour }}}-Z c+E
$$

where

tc is the civil time in hours.

Zc is the time zone GMT in hours.

$E$ is the equation of time.

(iv) Hour angle (degree $\left[{ }^{\circ}\right]$ ):

$$
\omega=(t s-12 h) * \frac{15^{\circ}}{\text { hour }}
$$


(v) Angle of incidence:

$$
\begin{gathered}
\cos \theta=\sin \delta * \sin \varphi * \cos \beta-\sin \delta * \cos \varphi * \sin \beta * \cos \gamma+\cos \delta * \cos \varphi * \cos \beta * \cos \omega+\cos \delta * \sin \varphi \\
* \sin \beta * \cos \gamma * \cos \omega+\cos \delta * \sin \beta * \sin \gamma * \sin \omega
\end{gathered}
$$

where

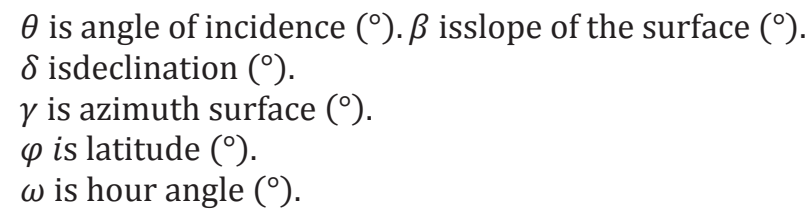

(vi) Zenith angle $\theta z\left(^{\circ}\right)$ :

$$
\cos \theta z=\cos \varphi * \cos \delta * \cos \omega+\sin \varphi * \sin \delta
$$

(vii) Extraterrestrial normal radiation, $G_{\text {on }}\left(\mathrm{kW} / \mathrm{m}^{2}\right)$ : :

$$
G_{o n}=G_{s c}\left(1+0.033 \cos \left(\frac{360 n}{365}\right)\right)
$$

Where $G_{s c}$ is equal $1.367 \mathrm{~kW} / \mathrm{m}^{2}$.

(viii) Extraterrestrial horizontal $G_{0}$ :

$$
G_{0}=G_{0 n} \cdot \cos \theta z
$$

(ix) Extraterrestrial horizontal radiation averaged over the time step $G_{0}$ :

$$
\overline{G_{0}}=\frac{12}{\pi}\left[\cos \varphi * \cos \delta *\left(\sin \omega_{2}-\sin \omega_{1}\right)+\frac{\pi\left(\omega_{2}-\omega_{1}\right)}{180^{\circ}} \sin \delta * \sin \varphi\right]
$$

(x) For a fixed clearness index, it is possible to obtain the global horizontal radiation on the earth's surface averaged over the time step $\bar{G}$ :

$$
\bar{G}=K_{t} \cdot \overline{G_{0}}
$$


(xi) Solar radiation is divided to calculate the diffuse radiation:

$$
\overline{\bar{G}} \overline{\bar{G}}=\left\{\begin{array}{c}
1-0.09 K_{t} \quad \text { for } k_{t} \leq 0.22 \\
0.9511-0.1604 k_{t}+4.388 k_{t}^{2}-16.638 k_{t}^{3}+112.336 k_{t}^{4} \\
0.165 \text { for } k_{t}>0.8
\end{array} \text { for } 0.22<k_{t} \leq 0.8\right\}
$$

(xii) The beam radiation is the rest of the horizontal radiation:

$$
\bar{G}=\overline{G_{b}}+\overline{G_{d}}
$$

(xiii) The three parameters that are necessary to obtain the horizontal radiation on a tilted surface are as follows:

$$
\begin{aligned}
& R_{b}=\frac{\cos \theta}{\cos \theta_{z}} \\
& A_{i}=\frac{\overline{G_{b}}}{\overline{\overline{G_{o}}}} \\
& f=\sqrt{\frac{\overline{G_{b}}}{\bar{G}}}
\end{aligned}
$$

The total radiation on the tilted surface is computed as follows $\overline{G_{t}}$

$$
\overline{G_{t}}=\left(\overline{G_{b}}+\overline{G_{d}} A_{i}\right) R_{b}+\overline{G_{d}}\left(1-A_{i}\right)\left(\frac{1-\cos \beta}{2}\right)\left[1+f * \sin ^{3} \frac{\beta}{2}\right]+\bar{G} \rho_{g}\left(\frac{1-\cos \beta}{2}\right)
$$

where

$\beta$ is the inclination of the surface panel.

$\rho_{\mathrm{g}}$ is ground reflectance or albedo in per unit.

(xiv) Output Power:

$$
\text { Power }=\overline{G_{t}} \cdot n_{p v} \cdot \text { rated }_{p v} \cdot \text { efficiency } y_{p v}
$$

where

$n_{p v}$ is the number of photovoltaic units.

Rated $_{p v}$ is the power rated of one photovoltaic

efficiency $y_{p v}$ is the efficiency in percentage. 


\subsection{Simulation of the Operation}

6. Operation of the system is simulated based on the following rules:

(i) Photovoltaic and wind generators produce as much power as possible for the solar radiation and/or wind speed in each time step.

(ii) If there is an excess of energy, as much as possible of this excess of energy is charged in the battery bank.

(iii) All four combinations of diesel generator on and off states (2 diesel generators by 2 possible states) are calculated for each time step. For each of these time steps, the order of priority to supply the necessary energy (demand-renewable generation) among dispatchable units (each diesel generator and the battery bank) is established based on the marginal cost per kWh of each unit. This means the unit with the lowest marginal cost supplies the necessary energy to cover demand. If this unit does not have the capacity to supply it all, then the unit generates its maximum power and the rest of diesel generators and the battery bank do the same until all demand is covered. In this way, the cost of supplying demand is minimized for each possible state of the system. The marginal cost per $\mathrm{kWh}$ for diesel generators is equal to its marginal fuel consumption per kW (slope of the fuel consumption curve) times the price of fuel as follows:

$$
\text { MarginalCost }_{d g_{i}}=a_{d g_{i}} \cdot D C
$$

7. The marginal cost per discharged kWh of the battery bank is its "battery wear cost," which can have any value introduced by the user. A logical value for this parameter can be calculated based on its lifetime throughput and its replacement cost as follows:

$$
\text { MarginalCost }_{\text {bat }}=b w c=\frac{\text { RepCost }_{\text {bat }}}{\text { lifetimeThroughput }_{\text {bat }}}
$$

8. The following flowcharts show how the dispatch decisions are implemented in Microsoft Excel. 


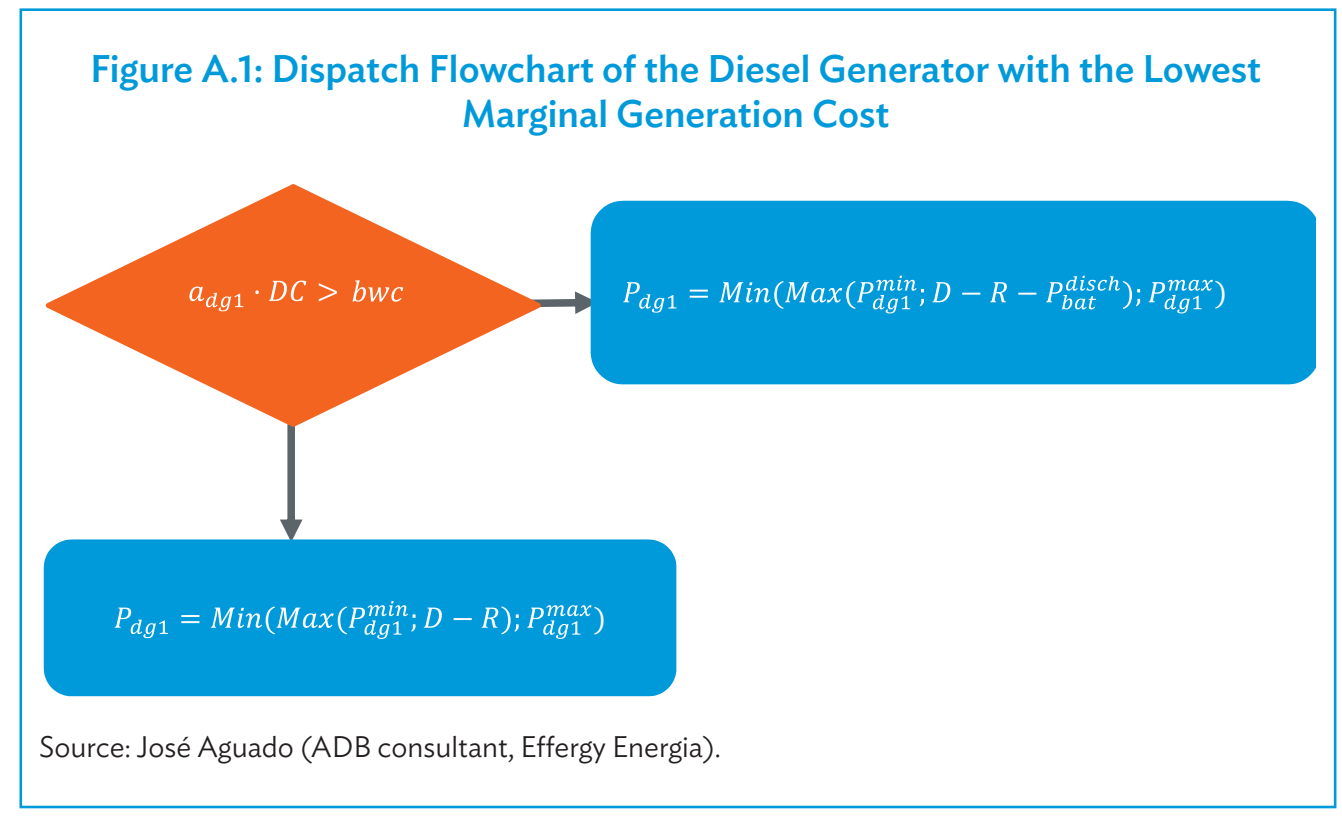

Figure A.2: Dispatch Flowchart of the Diesel Generator with the Highest Marginal Generation Cost

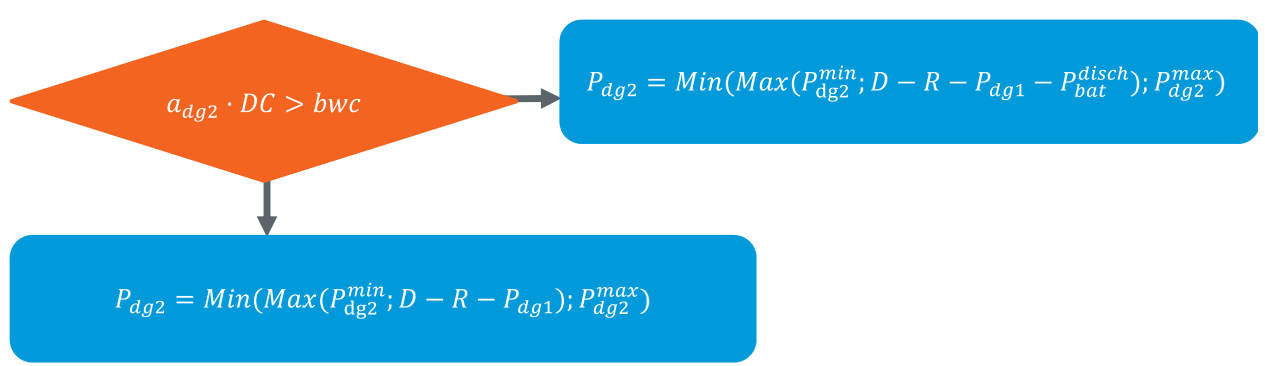

Source: José Aguado (ADB consultant, Effergy Energia).

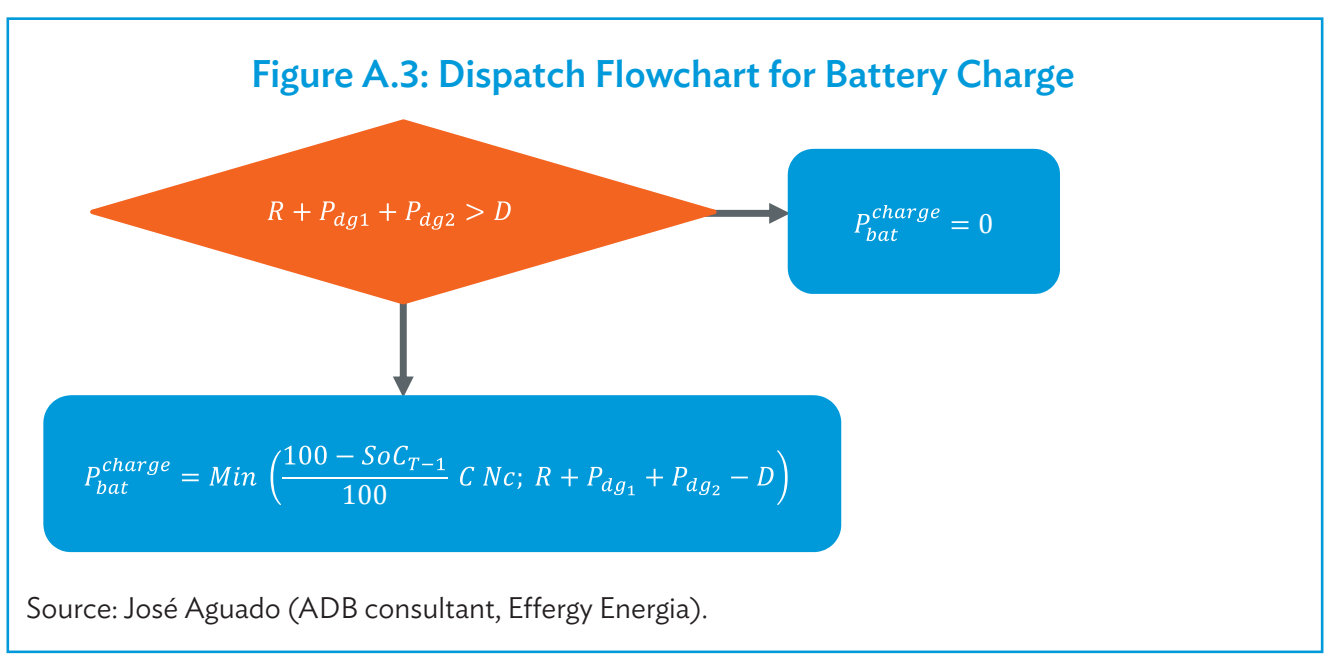




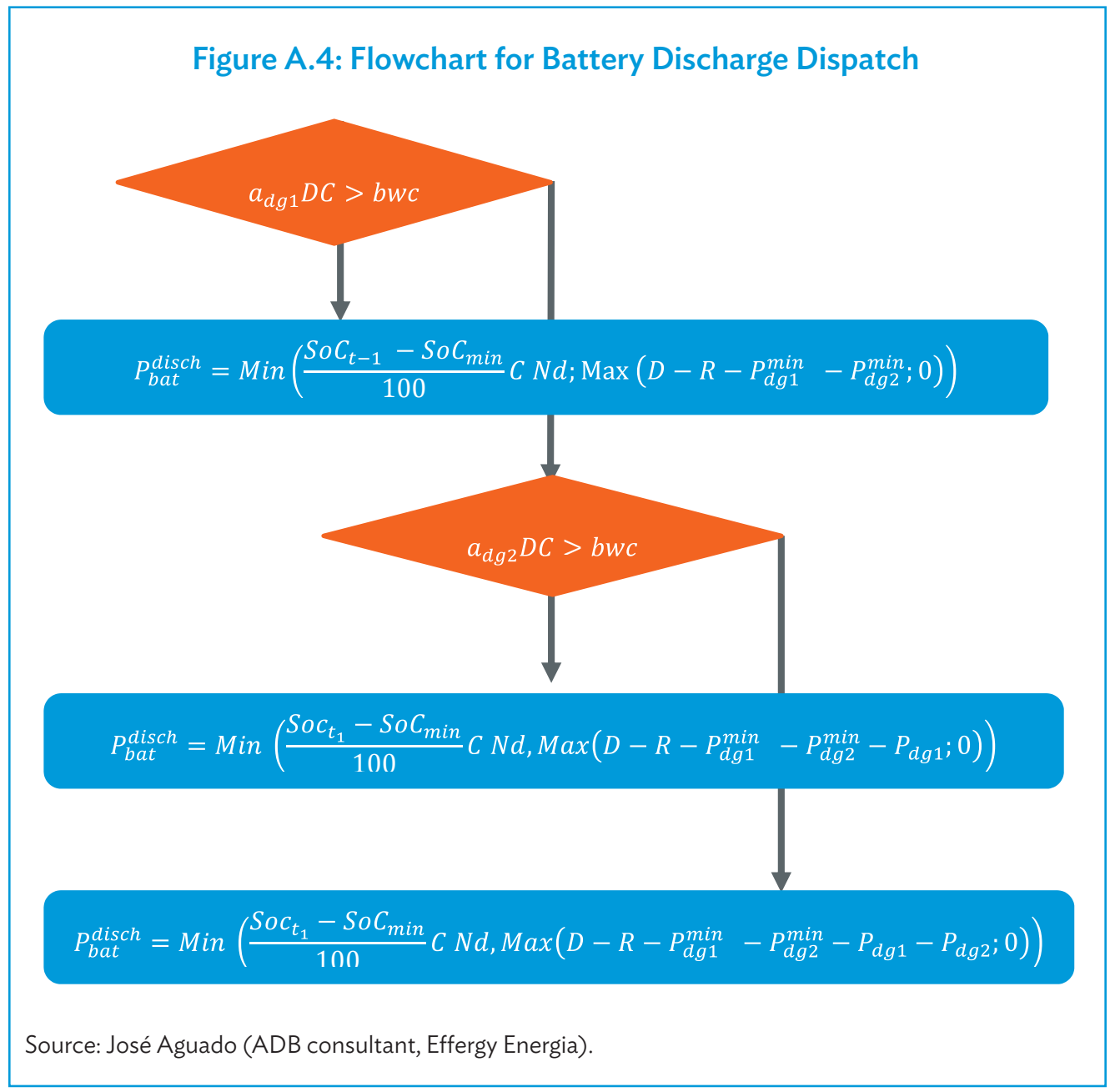

9. Out of the four possible diesel generator set state combinations, the one with the lowest cost that fulfills all constraints is chosen.

This cost is computed as follows:

$$
\text { Operating Cost }=\left(O \& M_{d g 1}+b_{d g 1}\right) u_{d g 1}+\left(O \& M_{d g 2}+b_{d g 2}\right) u_{d g 2}+a_{d g 1} P_{d g 1}+a_{d g 2} P_{d g 2}+b w c P_{b a t}^{d i s c h}
$$

The constraints that must be fulfilled are the following:

- Power Balance:

$$
D<R+P_{d g 1}+P_{d g 2}+P_{b a t}^{d i s c h}
$$


- Spinning Reserve:

$u_{d g 1}\left(P_{d g 1}^{\max i}-P_{d g 1}\right)+u_{d g 2}\left(P_{d g 1}^{\operatorname{maxi}}-P_{d g 1}\right)+Q_{a}^{t-1}>R_{l} * P_{l o a d}+R_{p v} P_{p v}+R_{w t} P_{w t}$

\subsubsection{Other Results}

10. The levelized cost of energy (LCOE) is the average cost of energy during the whole life of the project expressed in $\$ / \mathrm{kWh}$. It is computed as follows:

$$
L C O E=\frac{N P C}{\sum_{i=0}^{\text {years }} \frac{\text { Load }}{(1+\text { int })^{\text {year }}}}
$$

where

- $N P C$ is net present cost $(\$)$ representing a sum of all annual cash flows discounted to present value of money using the real interest rate.

- Int is interest rate (\%).

- Year is the year of the project.

- Years are years of the project.

11. Renewable energy fraction is the percentage of demand that is considered to be supplied by renewable sources. It is computed as follows:

$$
\% R E N=1-\frac{\text { Energy generated by Diesel Generator Sets }}{\text { Total Demand }}
$$




\section{REFERENCES}

[1] V. A. Graham and K. G. T. Hollands. 1988. A Time Series Model for Clearness Index with Application to Global Synthetic Weather Generation Solar Energy. 40. pp. 83-92.

[2] William Surles. Solar Angles and Tracking Systems. On-line available at https://www. teachengineering.org/lessons/view/cub_pveff_lesson01

[3] J. Manwell and J. McGowan. 1993. Lead Acid Battery Storage Model for Hybrid Energy Systems. Solar Energy. 50. pp. 399-405.

[4] J. Manwell and J. McGowan. 1994. Extension of the Kinetic Battery Model for Wind/ Hybrid Power Systems. In Proceedings of the 5th European Wind Energy Association Conference (EWEC'94). pp. 284-289.

[5] J. Manwell and J. McGowan. 2002. Wind Energy Explained. New York: Wiley. 


\section{Microsoft Excel-Based Tool Kit for Planning Hybrid Energy Systems: \\ A User Guide}

The Asian Development Bank has implemented a regional technical assistance to develop small hybrid renewable energy systems that will provide reliable, adequate, and affordable energy for inclusive growth in Asian rural areas, and enable access to electricity and energy efficiency in remote rural locations and small isolated islands. A Microsoft Excel-based Tool Kit, prepared as part of knowledge development activities of the technical assistance, is intended to support planning hybrid renewable energy systems based on experiences of pilot projects in South Asian developing member countries. It will help find the most cost-effective configuration for a hybrid renewable energy stand-alone system through simulation of operation for each possible configuration of the system.

\section{About the Asian Development Bank}

ADB's vision is an Asia and Pacific region free of poverty. Its mission is to help its developing member countries reduce poverty and improve the quality of life of their people. Despite the region's many successes, it remains home to a large share of the world's poor. ADB is committed to reducing poverty through inclusive economic growth, environmentally sustainable growth, and regional integration.

Based in Manila, ADB is owned by 67 members, including 48 from the region. Its main instruments for helping its developing member countries are policy dialogue, loans, equity investments, guarantees, grants, and technical assistance. 